\title{
New Method for Predicting the Performance of Solar Pond in any Sunny Part of the World
}

\author{
Adel O. Sharif*, Hazim Al-Hussaini, Ibrahim A. Alenezi \\ Centre for Osmosis Research \& Applications, Chemical \& Process Engineering Department, Faculty of \\ Engineering \& Physical Sciences, Surrey University, UK. \\ * Corresponding author: Tel: +44(0)1483 686584; F: +44(0)1483 686584; email: a.sharif@surrey.ac.uk
}

\begin{abstract}
The solar pond is considered one of the most reliable and economic solar systems. The collecting and storing of the solar energy is in one system, so the heat in summer can be utilised in winter in the same system. To predict the potential of solar pond at any part of the world a mathematical model is established to calculate the parameters affecting the performance of the solar pond through a computer programme.. The solar radiation input to the pond is calculated using the daily monthly average method. One dimensional steady state and transient assumptions in the gradient zone are used to predict the effect of any parameter on the solar pond performance. The results show excellent agreement with the experimental data under the steady state assumption. Many parameters affecting the performance of the solar pond such as shading effect, depths of the upper, gradient and storage zones, ground temperature and covered insulation for different climates and different latitudes have been studied. The results show that the solar pond has high potential even for colder climates such as that of the UK, where the heat could be used for a number of applications including domestic and industrial.
\end{abstract}

Keywords: Solar Pond, Solar Energy, Modelling

\section{Nomenclature}

$N$ the number of the day in the year

$\varphi$ latitude of the location..........degree

$\theta$ the Incident angle ............. degree

$I_{s c}$ Solar constant ................W. W. ${ }^{-2}$

$I_{o}$ the average daily extraterrestrial solar irradiance ....................W.W. $\mathrm{m}^{-2}$

$\delta$ the declination angle ......... degree

$\omega_{s}$ hour angle degree

$I_{\text {od }}$ is daily total direct normal extraterrestrial radiation .........W.W. $m^{-2}$

$I B F$ the fraction of the extraterrestrial radiation

Fc the monthly correction factor

$\bar{H}_{T}$ the monthly daily-average total irradiation on a horizontal surface ......W. W. ${ }^{-2}$

$H_{O T}$ the total extraterrestrial radiation on a horizontal surface .............W. W. ${ }^{-2}$

$\rho \quad$ water density..... $\mathrm{kg} \cdot \mathrm{m}^{-3}$

$C_{p}$ specific heat ........... $\mathrm{kg}^{-1} . \mathrm{C}^{-1}$

A Area ...... $\mathrm{m}^{2}$

$x \quad$ the depth .......m
$T$ temperature........ ${ }^{\circ} \mathrm{C}$

$Q_{\text {sru }}$ absorbed heat of solar radiation in the upper zone.............W. W. ${ }^{-2}$

$Q_{u w}$ heat loss from the sides in the upper zone.............W. W. $\mathrm{m}^{-2}$

$Q_{u b}$ heat gained from the bottom in the upper zone.............W. W. $\mathrm{m}^{-2}$

$Q_{u c}$ he at loss by convection in the upper zone.............W. W. $\mathrm{m}^{-2}$

$Q_{u r}$ he at loss by radiation in the upper zone.............W. W. ${ }^{-2}$

$Q_{u e}$ heat loss by evaporation in the upper zone..............W. W. $\mathrm{m}^{-2}$

$Q_{s r s}$ absorbed heat of solar radiation in the storage zone..............W. W. $\mathrm{m}^{-2}$

$Q_{s w}$ heat loss from the sides in the storage zone.............W. W. ${ }^{-2}$

$Q_{s b}$ heat loss from the bottom in the storage zone.............W. W. ${ }^{-2}$

$Q_{s t}$ heat loss from the top in the storage zone.............W. W. $\mathrm{m}^{-2}$

$Q_{\text {se }}$ heat loss by heat extraction in the storage zone.............W. W. ${ }^{-2}$ 


\section{Introduction}

Natural water temperature gradients was observed and reported first time by Kalecsinsky in the Medve Lake in Transylvania in 1902 [1,2]. This observation suggested the possibility of constructing and using the ponds as solar energy collectors and storage areas. Tabor (1964), Weinberger (1964), and Tabor and Matz (1965) reported a series of theoretical and experimental studies of these salt gradient ponds [3].

The solar pond is one of the simplest methods that can directly collect and convert solar energy to thermal power. Moreover, it is a solar power collector and a thermal storage unit at the same time. All Ponds convert solar radiation to heat although most of them lose that heat as a result of convection and evaporation. In nature when the sun's rays fall on the lake or the pond, the temperature of water increases gradually towards the bottom of the pond. Therefore, the water in the bottom becomes warmer then it rises to the surface and loses its heat to the atmosphere, a phenomenon called convection. However, the solar pond technology inhibits this phenomenon by dissolving salt into the bottom layer of this pond, making the fluid too heavy to rise to the surface, even when being hot. This idea can increase the temperature of the bottom layer up to more than $100 \mathrm{oC} \mathrm{[4].} \mathrm{Once} \mathrm{a} \mathrm{high} \mathrm{temperature} \mathrm{is} \mathrm{obtained,} \mathrm{the} \mathrm{bottom}$ layer can be used as a heat source to provide continuous heat through a heat exchanger at any time. The solar pond principle is to prevent vertical convection and/or evaporation according to the type of the solar ponds [5].

A typical salinity-gradient solar pond consists of three main zones as shown in Fig. 1:

- The Upper Convecting Zone (UCZ) which has the least cost, salinity, temperature, and is close to ambient temperature. The thickness of this zone is typically $0.3 \mathrm{~m}$ and it should be kept as thin as possible. The cost of constructing the $\mathrm{UCZ}$ is usually reasonable.

- The Non-Convecting Zone (NCZ) which is located between the upper and the lower zones of the pond. S ince the temperature and salinity increase with depth, this layer is not homogeneous. If the salinity gradient is large enough, the NCZ inhabits a convection phenomenon even when the lower zone is hotter.

- The Lower Convecting Zone (LCZ), which is a homogenous layer and has a relatively high salinity and high temperature. Heat is stored in this zone and can be exchanged in or out of the pond. As the LCZ's depth increases, the heat capacity increases and the temperature variation decreases.

Water surface

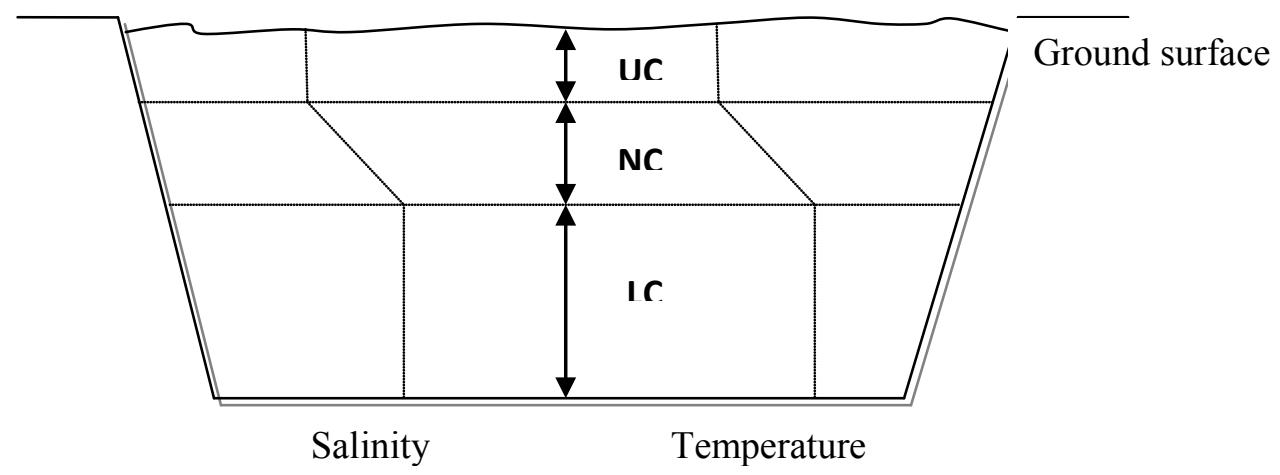

Fig. 1. Salinity and temperature profiles through the salinity gradient solar pond zones. 
Non-convective solar ponds can provide heat for domestic, agricultural, industrial, power generation and desalination purposes. More details about solar pond c onstruction and limitation can be obtain from [1], [2] and [4].

\section{Methodology}

Solar irradiation data have been widely measured and recorded for almost every region in each country in the world for many years. Nevertheless, the predictions and calculations of the irradiation are sometimes required to obtain a good approximation of the irradiation.

According to a solar pond location, the sun path in the sky is changed seasonally thus the sun's altitude and azimuth angle and the daily sunshine period are varied and cause a great effect on the amount of the incident solar radiation and then on the performance of the solar collector.

It is found that monthly averaged data are the most effective for representing the climate changes and calculations, since hourly and daily calculations and measurements are changed from year to another and are quite short to represent a general impression about the climate. In addition to this, seasonal and yearly readings cannot accurately represent the climate computations. Thus, averaged monthly measurements or computations have been adapted in this study.

Matlab computer software has been used to build a multi-scripts programme to solve ordinary differential equations by finite difference method for steady state models. This programme takes into account the changes of boundary conditions and surround factors with time.

This solar radiation computation program requires only a latitude value to predict sunrise, sunset and sunshine period to compute the solar radiation equations. A new predicted empirical equation has been added to this script to give a good agreement and it has been tested for three different locations in the middle east which are Kuwait, Riyadh and Jerusalem. The incident solar radiation values, based on monthly average daily amounts can be obtained from the available references or the 22 years average values which are recorded in NASA website [6].

Since the earth-sun distance varies each season, the apparent extraterrestrial solar irradiation changes during the year. Therefore, the solar irradiation intensity depends on the number of the day in the year. The average daily extraterrestrial solar irradiance is given by

$$
I_{o}=I_{S C}\left[1+0.0033 \cos \left(\frac{360 N}{370}\right)\right]
$$

Solar constant ( Isc ) value has been measured by many researchers since the beginning of the 20th century. Abbot [7] and his team in Smithsonian Institute after many research proposed the value of $1353 \mathrm{~W} / \mathrm{m}^{2}$ to be the value of the solar constant. Many further investigations were made on ground-base and high altitude measurements and eventually $1353 \mathrm{~W} / \mathrm{m}^{2}$ has been accepted to be the standard for the solar constant. NASA, after many measurements on the space, has recommended this value as well [8]. It has very recently been published in NASA's 
website that the generally accepted value of the solar constant is $1368 \mathrm{~W} / \mathrm{m}^{2}$ as a satellite measured yearly average, which is close to the standard value.

The total daily extraterrestrial radiation on a horizontal surface can be computed by

$$
H_{o T}=\frac{I_{o d}}{\pi}\left[\cos \theta \cos \delta \sin \omega_{s}+\frac{2 \pi \omega_{s}}{360} \sin \varphi \sin \delta\right]
$$

Where $I_{o d}$ is daily total direct normal extraterrestrial radiation and can be obtained by yielding the value of extraterrestrial radiation solar irradiation throughout the day as the following

$$
I_{o d}=24 I_{o}
$$

To use these equations for computation of the monthly daily-average total extraterrestrial radiation on a horizontal surface $\bar{H}_{O T}$, the month representative-day is needed and given by lunde[9] in addition to other useful equations in solar radiation calculations. The new empirical equation which works with available solar radiation equations to estimate the solar radiation based on a single input parameter is

$$
I B F=\frac{1.5 \varphi-14.25}{\varphi} F C
$$

Where $\mathrm{Fc}$ is a predicted monthly correction factor validated accurately for the Middle East with NASA published date and the above equation can be utilized in the following formula;

$$
\bar{H}_{T}=\operatorname{IBF}\left(\bar{H}_{O T}\right)
$$

$\mathrm{Eq}(5)$ is a well known formula in the solar radiation equations which are expansively explained in [9] based on the cloudiness (or clearness) index, however, the index here is substituted by the predicted factor ,IBF, which is obtained by linking the field solar radiation data with longitudes in a special computer programme.

The steady state model for a solar pond ha s been widely adopted by the most famous researchers in the SGSP field such as Weinberger [10], Rabl and Nielsen [11], Kooi [12], Ali [13], Wang and Akbarzadeh [14] and many of other researchers. A downward onedimensional flux model is often used for simplification purposes. The convective zones (upper and storage layers) are assumed to be well thermally mixed i.e. lumped systems. The upper layer steady state equation is:

$$
\rho_{u} C_{p u} A x_{u} \frac{d T_{u}}{d t}=Q_{s r u}+Q_{u b}-Q_{u c}-Q_{u r}-Q_{u e}
$$

The gradient layer is considered as a conduction slab and all absorbed solar radiation is consumed in building and maintaining the temperature profile in this layer. The storage zone steady state correlation will be

$$
\rho_{s} C_{p s} A x_{s} \frac{d T_{s}}{d t}=Q_{s r s}-Q_{s t}-Q_{s b}-Q_{s w}-Q_{s e}
$$


More details about each parameter in $\mathrm{Eq}(6)$ and $\mathrm{Eq}(7)$ are given by Lunde[9], Rable and Nielson[11] and Ali[13].Model validation is possibly the most essential step in the model building stages. In this study, the model validation is applied to Ali's study in Kuwait [13].

\section{Results}

The single input program is used to calculate the solar radiation in Kuwait, Riyadh and Jerusalem. The output of this script is compared with NASA average 22 year measurements data and the results are really good and shown in Fig. 2 for Kuwait, Fig. 3 for Riyadh and Fig. 4 for Jerusalem solar radiations.

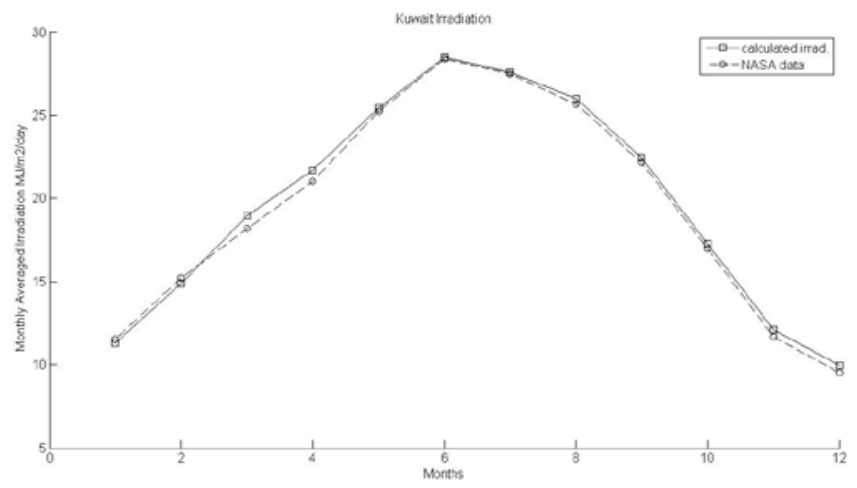

Fig. 2. NASA data and calculated solar irradiation for Kuwait.

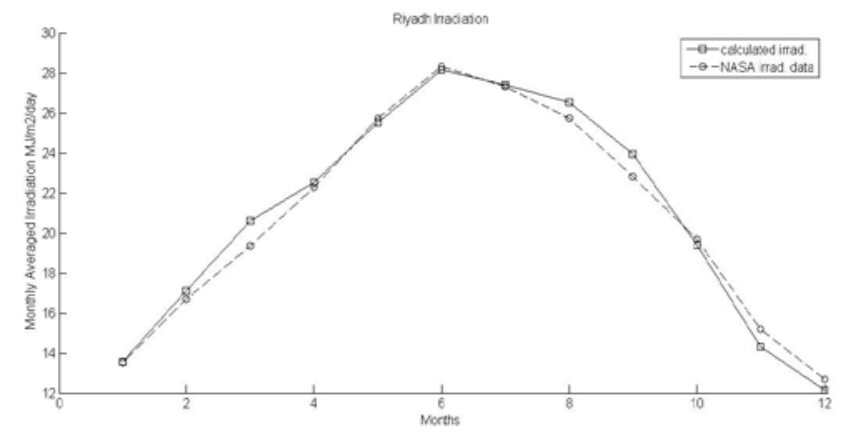

Fig. 3. NASA data and calculated solar irradiation for Saudi Arabia, Riyadh. 


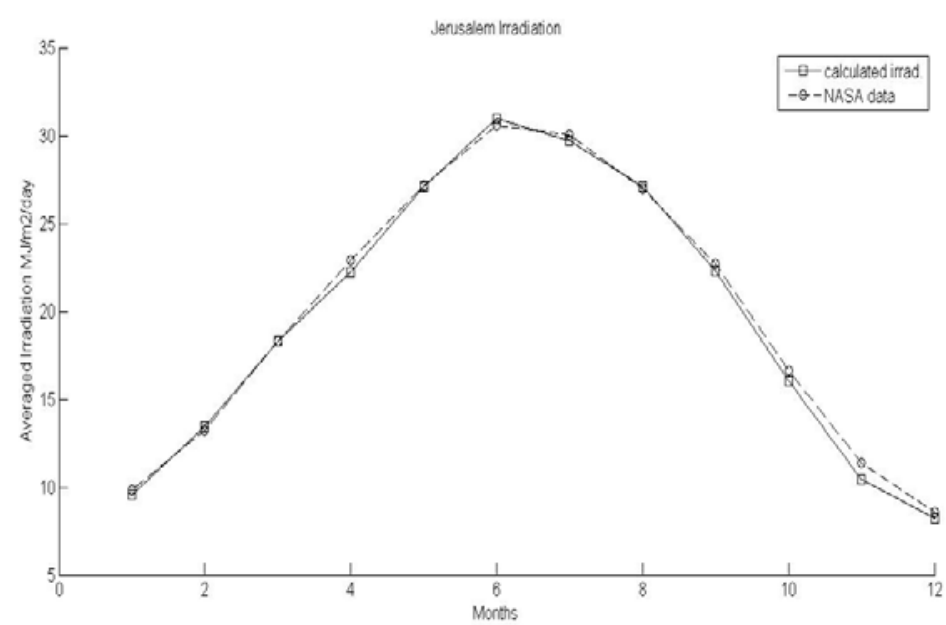

Fig. 4. NASA data and calculated solar irradiation for Jerusalem.

The obtained solar radiation data is used for one-dimensional time-dependent steady state program to predict the solar pond temperature behaviour in the storage zone during a year and an excellent agreement is obtained comparing with real temperature measurements by Ali [13] and this output and measured data are illustrated in Fig. 5.

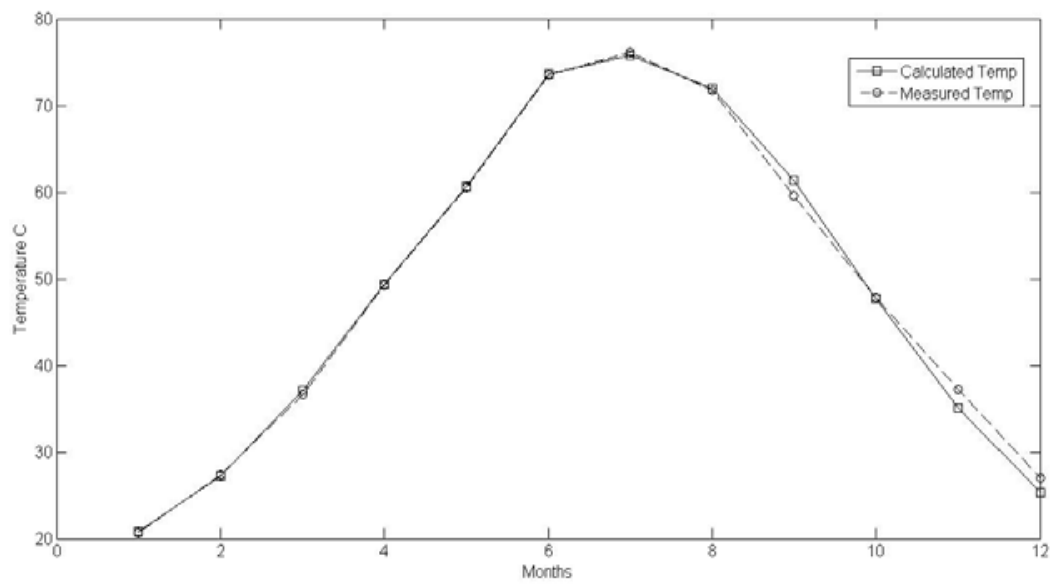

Fig. 5. Measured and calculated storage zone temperature in Kuwait solar pond.

The program can predict the performance of a solar pond in a cold climate location and for this purpose the University of Surrey in the UK has been chosen. The result is plotted in Fig. 6 and the storage zone temperature behaviour can be improved by changing the depth of the solar pond layers to reach $80{ }^{\circ} \mathrm{C}$. 


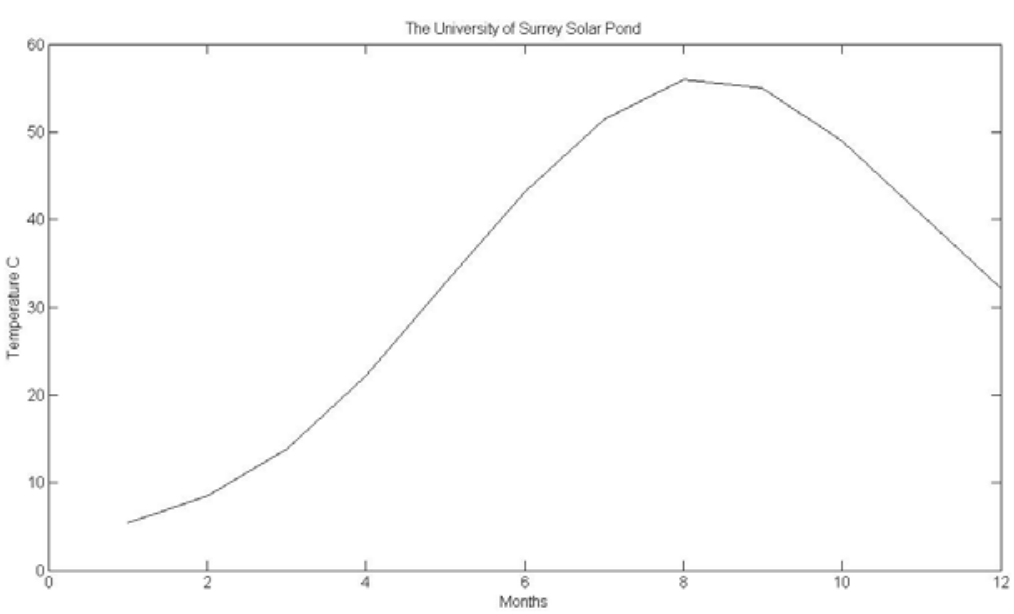

Fig. 6. Surrey storage zone $(1 \mathrm{~m})$ temperature at $1 \mathrm{~m}$ depth of gradient zone.

\section{Conclusions}

The proposed method provides an accurate prediction of the solar radiation based on a single input data which is the location latitude. The predicted results are validated by comparison with NASA 22 years averaged data in three various locations in the Middle East, where very close agreement has been obtained. The one-dimensional time-dependant steady state model has shown excellent agreement with Kuwait solar pond m easurement data. The transient model was investigated as well. However, it was found that the steady state model provided more realistic results. The solar pond performance in cold climate locations such as the UK has been studied and the pond temperature can reach $80{ }^{\circ} \mathrm{C}$ levels using some designs.

\section{References}

[1] W. C. Dickinson and P. N. Cheremisinoff, "Solar Energy Technology Handbook" Marcel Dekker, New York, (1980) 374.

[2] J. F. Kreider and F. Kreith "Solar Energy Handbook" McGraw-Hill, New York (1981) $10-2$

[3] J. A. Duffie, and W. A. Beckman 'Solar Engineering of Thermal Processes'" 3rd Ed. , John Wiley \& Sons (2006) 652.

[4] H. M. Lu, A. H. P. Swift, H. D. Hein and J. C. Walton, "Advancements in salinity gradient solar-pond technology based on sixteen years of operational experience' J. Sol. EnergyTrans. ASME 126 (2004) 759-767.

[5] J. F. Kreider and F. Kreith "Solar heating and Cooling Active and Passive Design" (1982) 284.

[6] NASA's Website http://www.eoearth.org/article/Solar_radiation

[7] C.G. Abbot 'The Solar Constant'” Solar Energy 9(2) (1965) 166-167.

[8] H. P. Garg 'Treatise on Solar Energy' V1, John Wiley \& Sons (1982).

[9] P. J. Lunde 'Solar Thermal Engineering'” John W New York (1980).

[10]H. Weinberger, 'The physics of solar ponds', Solar Energy 8 (1964) 45.

[11]A. Rabl and C. E. Nielsen, "Solar Ponds for Space Heating" Solar Energy 17 (1975) 1-12. 
[12]C. F.Kooi, "The steady state salt gradient solar pond" Solar Energy 23 (1979) 37-45.

[13]H. M. Ali " Mathematical modeling of salt gradient solar pond performance" Energy Research 10 (1986) 377-384.

[14]Y. F. Wang and A. A. Akbarzadeh, "A parametric study on solar ponds" Solar Energy 30 (1983) 555-562. 